\title{
Gündoğan (Ardeşen-Rize) Köyü Yerleşim Alanındaki Yamaç Duraysızlığının Jeoteknik Açıdan İncelenmesi
}

\author{
Ayberk Kaya ${ }^{1, *}$, Cem Demirbaş ${ }^{1}$, Serhat Dağ ${ }^{2}$ \\ ${ }^{1}$ Recep Tayyip Erdoğan Üniversitesi, Mühendislik Fakültesi, Jeoloji Mühendisliği Bölümü, 53100, Rize. \\ ${ }^{2}$ Gümüşhane Üniversitesi, Mühendislik ve Doğa Bilimleri Fakültesi, Jeoloji Mühendisliği Bölümü, 29100, Gümüşhane.
}

\section{Özet}

Bu çalışma kapsamında Gündoğan (Ardeșen-Rize) Köyü yerleșim alanının üstünde bulunduğu yamaçta meydana gelen ve yaklaşık olarak 2.24 hektarlık bir alanı kapsayan duraysızlık problemi jeoteknik açıdan incelenmiş̧tir. Yapılan çalı̧̧alar sırasıyla arazi, laboratuvar ve şev duraylılık analizi çalışmaları olmak üzere üç aşamada yürütülmüştür. Bu amaçla eğim yönünde 3 hat boyunca toplam $150 \mathrm{~m}$ derinliğinde 6 adet sondaj kuyusu açılmış, 3 profilde jeofizik çalışmalar gerçekleştirilmiş ve 2 sondaj kuyusunda inklinometre ölçümleri yapılmıştır. Arazi çalışmaları sonucunda ana kayayı Geç Kretase yaşlı Çağlayan Formasyonu'na ait volkanotortul kayaçların oluşturduğu ve bu birimlerin üzerine kalınlı̆̆ 5.0-16.5 m arasında değişen yamaç molozunun geldiği belirlenmiştir. Yamaç molozunun fiziko-mekanik özelliklerini tespit etmek için araştırma sondajlarından örselenmemiş örnekler alınmıştır. Arazi ve laboratuvar çalıșmalarından elde edilen veriler yardımıyla Limit Denge ve sonlu elemanlar tabanlı Kayma Dayanımı Azaltma Yaklaşımı (FEM-SSR) yöntemleri kullanılarak duraylılık analizleri yapılmış ve sonuçlar karşılaştırılmıştır. Duraylılık analizleriyle belirlenen kayma yüzeylerinin dağılımları incelendiğinde yamaçta önlem alınmaması durumunda yenilmenin gerileyen șekilde devam edebileceği saptanmıştır. Yapılan inklinometre ölçümleri ve duraylılık analizleri, Gündoğan Köyü yerleşim alanındaki yamaç molozunun duraysız olduğunu ve heyelan potansiyeli taşıdı̆̆ını göstermektedir.

Anahtar Sözcükler

Duraylılık Analizi, FEM-SSR Yöntemi, Limit Denge Yöntemi, Güvenlik Sayısı, İnklinometre Ölçümleri

\section{Geotechnical Investigation of the Slope Instability in the Gündoğan Village Settlement Area (Ardeşen-Rize)}

\begin{abstract}
In the scope of this study, the slope stability problem in the Gündoğan (Ardeşen-Rize) village settlement area covering approximately 2.24 hectares was investigated by means of geotechnical way. The studies were performed in three stages as field, laboratory works and slope stability analyses. For this purpose, along the three survey lines; six boreholes with a total of 150 meters in length were drilled, geophysical studies were performed along the three lines and inclinometer measurements were taken in two boreholes. At the end of the field work, it was determined that the talus whose thickness varies between 5.0 and 16.5 meters overlies the parent material that was formed by the Late Cretaceous-aged Çăglayan Formation consisting of volcano-sedimentary rocks. To determine the physicomechanical properties of the talus, undisturbed samples were taken from boreholes. Limit equilibrium and the Finite Element based Shear Strength Reduction (FEM-SSR) methods were used to perform stability analyses using the obtained data from field and laboratory studies and the results were compared. When examining the distribution of the failure surfaces obtained from the stability analyses, it was detected that the failure may continue as retrogressive type if there is not any precaution taken on the slope. Performed inclinometer measurements and stability analyses showed that the talus in the Gündoğan village settlement area is unstable and has a landslide potential.
\end{abstract}

$\underline{\text { Keywords }}$

Stability Analysis, FEM-SSR Method, Limit Equilibrium Method, Factor of Safety, Inclinometer Measurements

\section{Giriş}

Sismik aktiviteler, aşırı ve şiddetli yağışlar, volkanik aktiviteler ve insanlar tarafindan doğaya müdahalelerin etkileri ya da bunların bir kısmının birleşik etkileri ile tetiklenen kütle hareketleri sonucunda her yıl binlerce insan hayatını kaybederken ülke ekonomileri milyarlarca dolar maddi zarara uğramaktadır. Doğal bitki örtüsünün tahrip edilmesi, gerekli hassasiyette jeoteknik çalışmalar gerçekleştirilmeden yerleşime açılan yamaçlarda yapı inşasına yönelik çalışmalar ile farklı amaçlarla gerçekleştirilen kazı ve patlatma çalışmaları heyelanları tetiklemektedir. Bunların yanı sıra nüfus artışına paralel olarak yeni yerleşim ve yapı alanlarına ihtiyaç artmaktadır. Ülkemizde afetlerden kaynaklanan can ve mal kaybına yönelik değerlendirmelerde heyelanlar depremlerin ardından ikinci sırada yer almaktadır.

* Sorumlu Yazar: Tel: +90 (464) 2237518-1175 Faks: +90 (464) 2237514

E-posta: ayberk.kaya@erdogan.edu.tr (Kaya A),cem_db@msn.com (Demirbaş C) serhatdag@gumushane.edu.tr (Dağ S)
Gönderim Tarihi / Received : 23/04/2018

Kabul Tarihi / Accepted : : 25/06/2018 
Bölgesel olarak ele alındığında ise Karadeniz Bölgesi’nde heyelanlar en fazla can kaybı ve ekonomik zarara sebebiyet veren doğal kaynaklı afetler olarak dikkat çekmektedir. Bölgenin iklim koşulları, morfolojik yapısı ve jeolojik koşulları heyelanların meydana gelmesinde en önemli etken olarak göze çarpmaktadır. Diğer doğal kaynaklı afetlerde olduğu gibi heyelanların da meydana gelme zamanı önceden kesin olarak belirlenememektedir. Ancak bilimsel veriler ve teknolojik çalışmalar neticesinde ulaşılan bilgilerle heyelan olması muhtemel bölgelerin kestirimi ve bu sayede heyelanlardan kaynaklı can ve mal kayıplarının en düşük seviyelere indirgenmesi mümkündür. Doğal kaynaklı afetlerden kaynaklanan zararların azaltılması ve canlı hayatın bu zararlardan en az seviyede etkilenmesi amacı ile heyelanlara yönelik olarak çok sayıda araştırma yapılmaktadır. Bilimsel gelişmelere paralel olarak heyelan kayıtlarının daha düzenli bir şekilde tutulması ve bölgesel düzeyde yapılan çalışmalar bu artışta etkili olmuştur (Dağ 2007).

Heyelanlara yönelik çalışmaları iki grupta toplamak mümkündür. Bunlardan birincisi bölgesel planlamalara yönelik olarak geniş alanları kapsayan bölgesel düzeyde yapılan çalışmalardır. Bu tür çalışmalar özellikle son çeyrek yüzyılda bilgisayar teknolojilerindeki gelişmelerden de yararlanarak üretilen ve heyelanların mekânsal dağılımlarını belirlemeye yarayan heyelan duyarlılık haritalarını konu alan çalışmalardır. Çok sayıda araştırmacı bu konuda farklı yöntemler kullanarak çalışma bölgelerine özgü parametreleri değerlendirerek bilimsel çalışmalar gerçekleştirmiş ve heyelan oluşumuna duyarlı alanların belirlenmesi yönünde toplumsal katkılar sunmuştur (Gökçeoğlu ve Aksoy 1996; Ercanoğlu ve Gökçeoğlu 2002; Ayalew vd. 2004; Yeşilnacar ve Topal 2005; Çan vd. 2005; Lee 2005; Castellanos Abella ve Van Westen 2007; Akgün ve Bulut 2007; Akgün vd. 2008; Nefeslioğlu vd. 2008; Kıncal vd. 2009; Pradhan vd. 2010; Sezer vd. 2011; Althuwaynee vd. 2012; Akgün vd. 2012; Dağ ve Bulut 2012; Ösna vd. 2014; Romer ve Ferentinou 2016; Samia vd. 2017; Reichenbach vd. 2018). Heyelanlara yönelik ikinci grup çalışmalar ise yerel duraysızlık problemlerinin araştırılması ve bu problemlerin çözümüne yönelik gerçekleştirilen jeoteknik çalışmaları içermektedir. Bu tür çalışmalarda limit denge ve sayısal analiz yöntemleri ile şevlerin dengede olup olmadıkları araştırılmaktadır. Bu çalışmalar duyarlılık haritalarına yönelik çalışmalara oranla dar alanlarda gerçekleştirilmekte ve o alanda yer alan yerleşim alanı veya mühendislik yapı alanlarının heyelanlardan etkilenmemesi için şev duraylılığına yönelik çözüm önerileri geliştirmektedir (Gürocak vd. 2008; Kahadateniya vd. 2009; Jeldes vd. 2013; Liu ve Zhao 2013; Avşar vd. 2014; Alemdağ vd. 2014, Alemdağ vd. 2015; Kaya vd. 2015, Kaya vd. 2016, Kaya vd. 2018).

Bu çalışma kapsamında, Gündoğan (Ardeşen-Rize) Köyü yerleşim alanının üstünde bulunduğu ve mahalle yolunun da üzerinden geçtiği yamaçta meydana gelen duraysızlık sorunu jeoteknik açıdan incelenmiştir. 1:25.000 ölçekli Artvin F46-d1 paftası içinde bulunan çalışma alanı, eski bir heyelan (paleo-heyelan) malzemesinin oluşturduğu 20-30 eğim açısı ile KD yönüne bakan bir yamacın üzerindedir (Şekil 1). Belirlenen uygun lokasyonlarda toplam $150 \mathrm{~m}$ derinliğinde 6 adet araştırma sondajı açılmıştır. 2 adet sondaj kuyusundan inklinometre ölçümleri alınmıştır. 3 profilde çok kanallı yüzey dalgası (MASW) yöntemi yardımıyla jeofizik çalışmalar yapılmıştır. Laboratuvar çalışmaları kapsamında araziden derlenen örselenmemiş ve örselenmiş zemin örnekleri üzerinde çalışmanın amacına uygun zemin mekaniği deneyleri gerçekleştirilmiştir. Arazi ve laboratuvar çalışmalarından elde edilen veriler yardımıyla limit denge analizi ve sayısal analiz (FEM-SSR) yöntemleri kullanılarak duraysızlık sorunu gözlenen yamaç için analizler yapılmıştır.

\section{2. Çalışma Alanının Jeolojisi}

Doğu Pontid Tektonik Birliği'nin Kuzey Zonu'nda yer alan çalışma alanında (Ketin 1966) Geç Kretase yaşlı Çağlayan Formasyonu'na ait kayaçlar ve Kuvaterner yaşlı yamaç molozları yüzeyleme vermektedir. Volkano-tortul karakterli bir istif olan Çağlayan Formasyonu, ilk defa Güven (1993) tarafından tanımlanmıştır. Formasyon andezit-bazalt ve bunların piroklastitleri ile genellikle kırmızı-bordo renkli biyomikrit, kireçtaşı, marn ve tüfit ara tabakalarından oluşmaktadır. Formasyonda gri-yeşil ve gri-morumsu bir renk tonu egemendir. Birimin yaşı, yapılan önceki çalışmalarda Geç Kretase (Kampaniyen-Maastrichtiyen) olarak belirlenmiştir.

Çalışma alanında yüzeyleme veren bazaltlar kırıklı-çatlaklı bir yapı sunmakta olup, gri-koyu gri renklidir. Bazaltlar sistematik olmayan gelişi güzel oluşmuş çatlaklar içermektedir. Çatlak yüzeyleri boyunca ayrışma gelişmiştir. Ayrışma rengi ise koyu kahve-sarı arasındadır. Sahada açılan yol yarmalarında kaya mostralarına son derece kısıtlı olarak rastlanılmaktadır. SK-2 ve SK-6 nolu araştırma sondajlarında ara seviye olarak marn ve tüfit seviyeleri kesilmiştir.

Yamaç molozu olarak tanımlanan zemin malzemesi çalışma alanının üstünde bulunduğu yamaç eteklerinde yoğun bir biçimde gözlenmekte olup, bunlar yamacın bulunduğu alandaki kayaç türlerine göre köşeli, yassı ve bazıları küt köşeli, blok, çakıl, kum, silt ve killerden oluşmuşlardır. Silt ve kil miktarı diğer bileşenlere göre daha yüksektir. Bloklar Çağlayan Formasyonu'ndan türemiş bazalt karakterli köşeli volkanik kayaçlardan oluşmaktadır. Çalışma alanında yüzeylenen heyelan kökenli yamaç molozunda yapılan arazi, sondaj ve jeofizik çalışmaları neticesinde birimin üstten alta doğru bloklu ve killi olmak üzere iki seviyeden oluştuğu belirlenmiştir.

Çalışma alanı ve çevresine ait jeoloji haritası Şekil 2'de verilmiştir. 


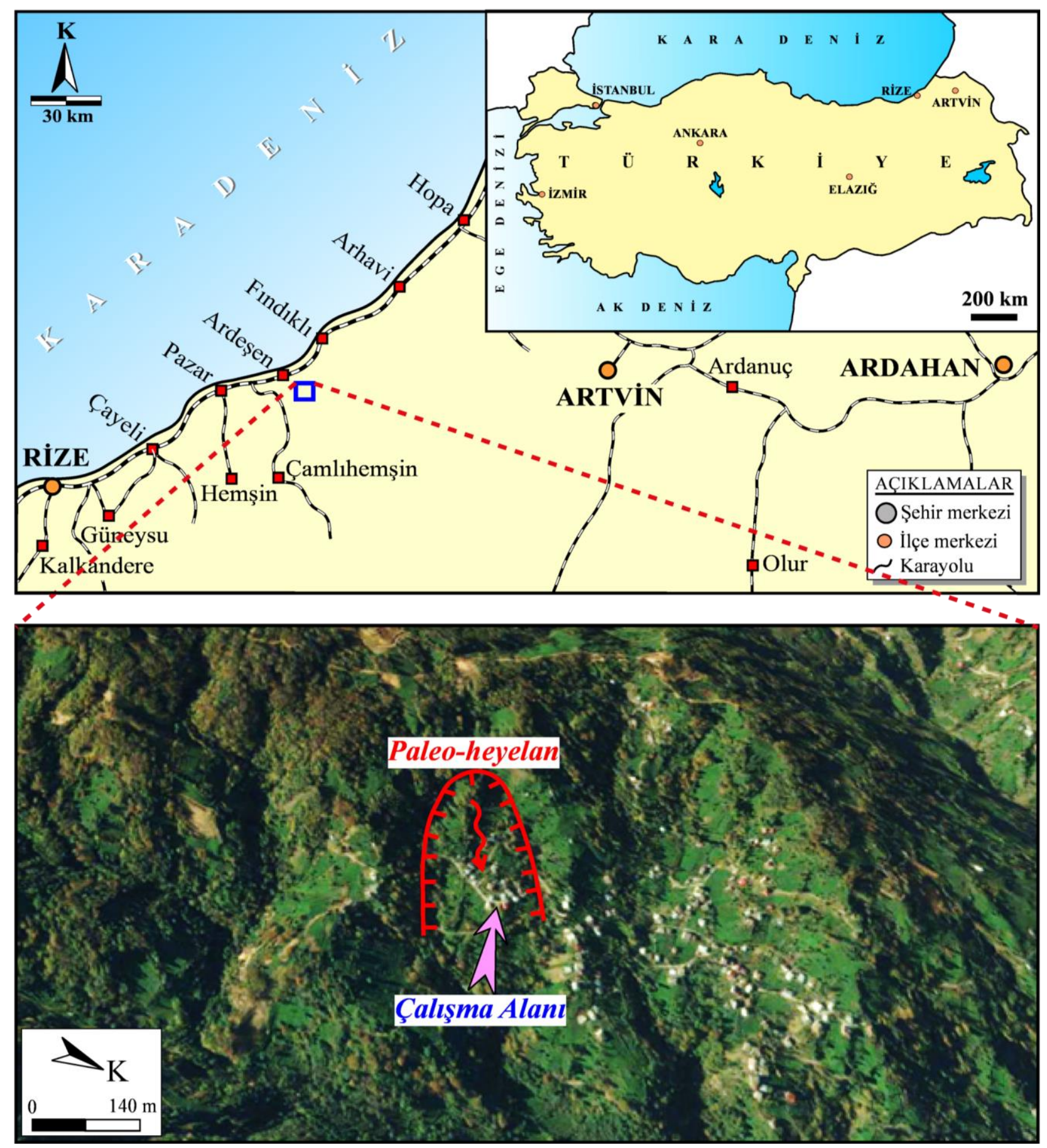

Şekil 1: Çalışma alanına ait yer bulduru haritası 


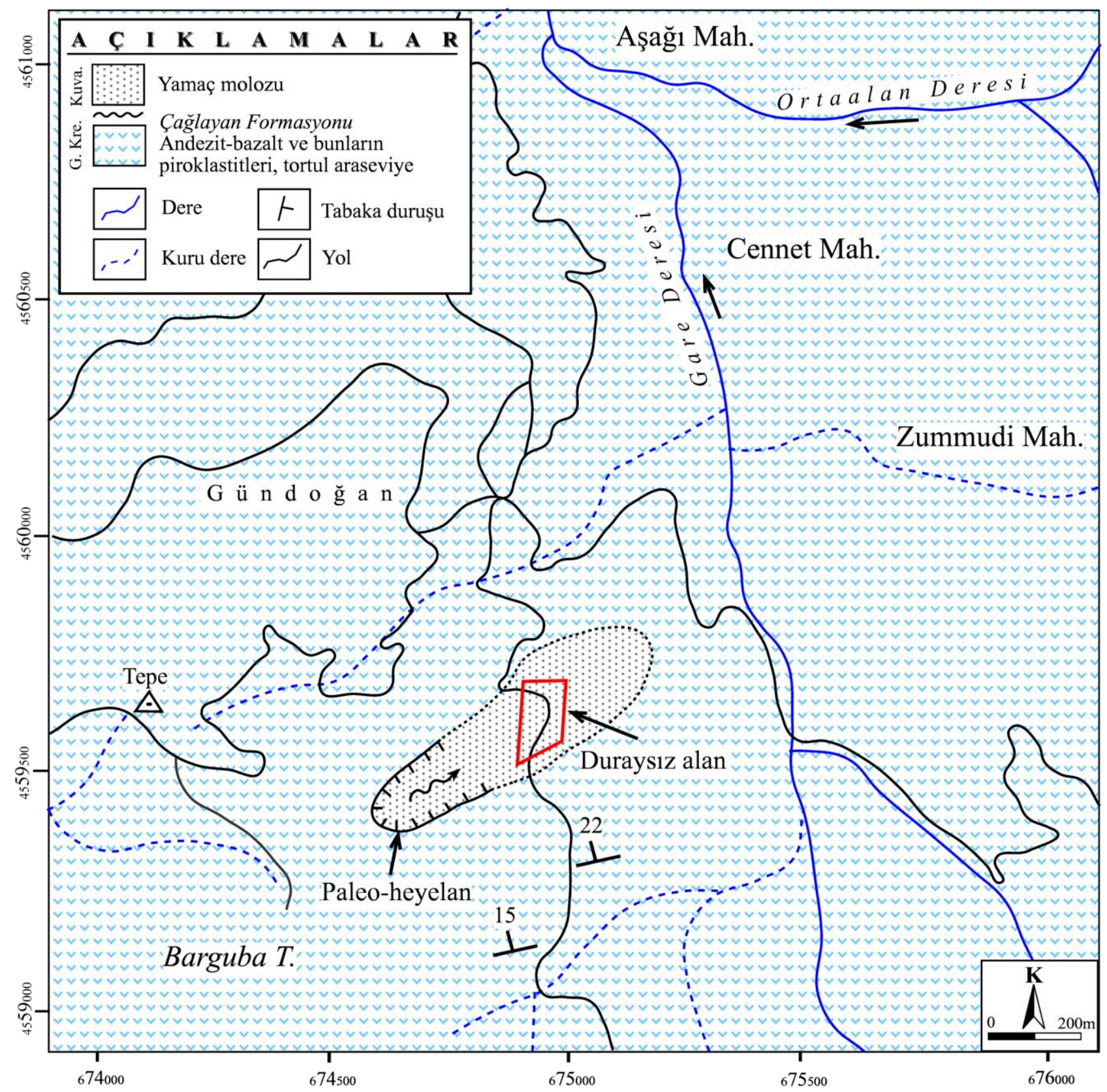

Şekil 2: Çalışma alanı ve çevresine ait jeoloji haritası

\section{Mühendislik Jeolojisi Çalışmaları}

08 Şubat 2016 tarihinde gerçekleşen aşırı yağışların sonrasındaki süreçte mahalleden geçen beton yoldan itibaren çatlaklar gelişerek arazide ve köy evlerinde deformasyonlar oluşmuştur. Bu alandaki beton yolda ve 4 adet evde ağır yapı hasarları meydana gelmiştir (Şekil 3). Yolda meydana gelen oturma miktarı yaklaşık 40 cm'ye kadar ulaşmış durumdadır. Sahada doğrusal hatlar boyunca sistematik şekilde oluşmuş üç adet ana çekme gerilmesi çatlağı gelişmiştir. Etkilenen alanın boyutları yaklaşık olarak 160x140 m (2.24 hektar) civarındadır. Bu duraysızlık problemini mühendislik jeolojisi açısından araştırmak amacıyla gerçekleştirilen çalışmalar arazi, laboratuvar ve şev duraylılık analizi çalışmaları olmak üzere üç aşamada yürütülmüştür. Yapılan çalışmalardan elde edilen sonuçlar aşağıdaki bölümlerde sunulmuştur. 

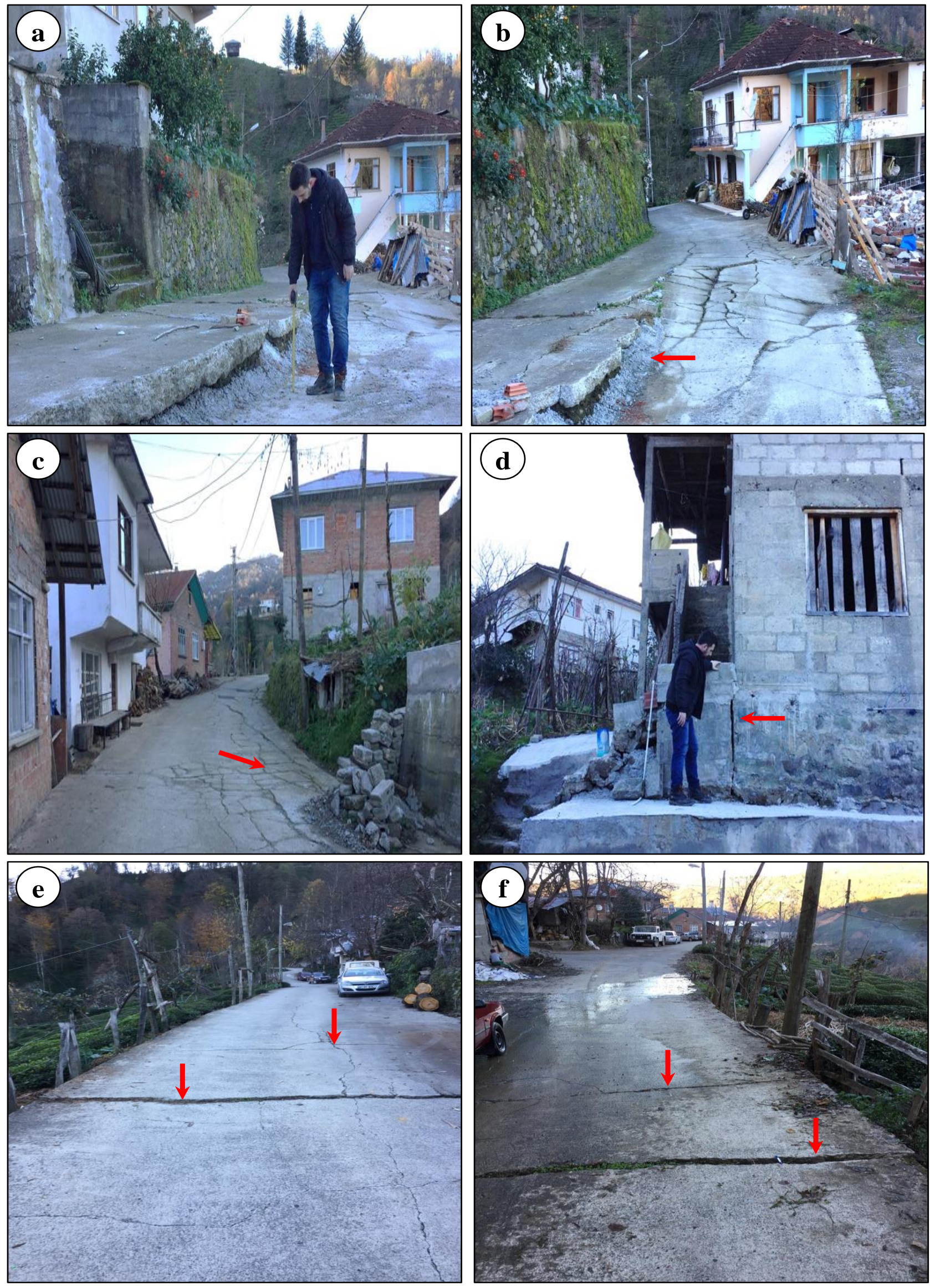

Şekil 3: Çalışma alanında meydana gelmiş çatlaklar ve oturmalar 


\subsection{Arazi Çalışmaları}

Arazi çalışmaları kapsamında yamaç boyunca 3 adet etüt hattı belirlenmiş ve bu hatlar boyunca yüzey ve yeraltı çalışmaları gerçekleştirilmiştir (Şekil 4). Çalışma alanı içinde yüzeylenen zeminle ilgili detaylı bilgiler elde etmek ve zeminin kalınlığındaki değişim aralıklarını net olarak tespit etmek amacıyla yeraltı suyu ölçümlerini de içerecek şekilde her biri 25 m derinliğinde olan 6 adet araştırma sondajı yapılmıştır. Bu sondajlardan SK-4 ve SK-5 Etüt Hatt1-1 üzerinde; SK-1 ve SK-3 sondajları Etüt Hattı-2 üzerinde, SK-2 ve SK-6 sondajları ise Etüt Hatt1-3 üzerinde bulunmaktadır (Şekil 4). Sondaj çalışmaları ana kayaya kadar inecek şekilde yapılmıştır. Yürütülen çalışmalar neticesinde yamaç molozu kalınlığının 5.0-16.5 m arasında değiştiği belirlenmiştir. Sondaj kuyularından yalnızca SK-2 nolu kuyuda yapılan ölçümlere göre yeraltı su tablasının yüzeyden $11.00 \mathrm{~m}$ derinlikte olduğu saptanmıştır (Tablo 1). Sondajlar $25 \mathrm{~m}$ ile sınırlı olduğundan diğer sondaj kuyularında ise bu derinlikte yeraltı suyuna rastlanmamıştır. Ancak, SK-1 nolu sondajın güneybatısında sürekli akış halinde olan bir su kaynağının varlığı yeraltı su seviyesinin bu lokasyonda yüzeye yakın olduğunu göstermektedir (Şekil 4, 6).

SK-4 ve SK-5 nolu sondaj kuyularına inklinometre borusu $(\varnothing: 70 \mathrm{~mm}$ ) yerleştirilerek 25 Temmuz-13 Kasım 2017 tarihlerini kapsayan dönemde inklinometre cihazı ile kuyu eksenlerinin düşey sapmaları tespit edilmeye çalışılmıştır. Ölçüm hassasiyetinin diğer yöntemlerden daha yüksek olması sebebiyle zeminde gelişebilecek çok yavaş hareketler bu yöntemle belirlenmeye çalışılmıştır. SK-4 nolu kuyuda yapılan inklinometre ölçümlerinde gözlenen hareketlerin genel olarak yüzeyden $4 \mathrm{~m}$ derinlikte yamaç molozu içindeki bloklu ve killi seviye dokanağına yakın bir yerde geliştiği tespit edilmiştir (Şekil 5). Ancak, SK-5 nolu sondaj kuyusunda yapılan okumalarda ise anlamlı herhangi bir hareketlilik saptanmamıştır. Dolayısıyla yenilmenin bu alandaki topuk kısmı, SK-4 ve SK-5 sondajlarının arasında kalmaktadır. Okuma aralıkları ve kaymanın yönü dikkate alındığında, ölçüm süresi boyunca gerçekleşen kaymanın $0.09 \mathrm{~mm} / \mathrm{gün}$ hızında KD yönüne doğru olduğu ve Varnes (1978) tarafından önerilen sınıflandırmaya göre "son derece yavaş hızlı heyelan" sınıfında olduğu belirlenmiştir. İnklinometre ölçümleri sonucunda saptanan küçük deformasyonlar kaymanın yavaşladığını, sahadaki ana deformasyonların ise Şubat 2016 tarihinden sonraki dönemde meydana geldiğini göstermektedir.

Sondaj yapılamayan lokasyonlarda zemin profilini ortaya çıkarmak ve P-S dalga hızları yardımıyla zeminin dinamik elastik parametrelerini belirlemek amaciyla 3 profil boyunca Seistronix RAS-24 marka sismograf kullanılarak MASW (Multichannel Analysis Surface Waves) yöntemi ile yüzey dalgası analizleri gerçekleştirilmiştir (Tablo 2, Şekil 4).

Tablo 1: Çalışma alanında yapılan sondajlara ait teknik bilgiler

\begin{tabular}{|c|c|c|c|c|c|}
\hline $\begin{array}{c}\text { Kuyu } \\
\text { no }\end{array}$ & $\begin{array}{c}\text { Kuyu } \\
\text { derinliği (m) }\end{array}$ & $\begin{array}{c}\text { Kuyu kotu } \\
(\mathbf{m})\end{array}$ & $\begin{array}{c}\text { YASS } \\
\text { derinliği (m) }\end{array}$ & $\begin{array}{c}\text { Y } \\
\text { (Sağa) }\end{array}$ & $\begin{array}{c}\text { X } \\
\text { (Yukarı) }\end{array}$ \\
\hline SK-1 & 25.00 & 418 & Yok & 423201 & 4559741 \\
\hline SK-2 & 25.00 & 411 & 11.00 & 423244 & 4559723 \\
\hline SK-3 & 25.00 & 405 & Yok & 423265 & 4559769 \\
\hline SK-4 & 25.00 & 403 & Yok & 423225 & 4559809 \\
\hline SK-5 & 25.00 & 390 & Yok & 423255 & 4559856 \\
\hline SK-6 & 25.00 & 380 & Yok & 423363 & 4559740 \\
\hline
\end{tabular}

Tablo 2: MASW yöntemine göre belirlenen dinamik-elastik parametreler

\begin{tabular}{|c|c|c|c|c|c|c|}
\hline Hat & Tabaka no & $\mathbf{H}(\mathbf{m})$ & $\mathbf{V}_{\mathbf{p}}(\mathbf{m} / \mathbf{s})$ & $\mathbf{V}_{\mathrm{s}}(\mathbf{m} / \mathbf{s})$ & $\mathbf{E}_{\mathbf{d}}(\mathbf{M P a})$ & $v$ \\
\hline \multirow{3}{*}{1} & 1 & 4.20 & 400 & 200 & 145 & 0.33 \\
\hline & 2 & 8.30 & 760 & 340 & 507 & 0.38 \\
\hline & 3 & - & 1100 & 500 & 1199 & 0.37 \\
\hline \multirow{3}{*}{2} & 1 & 7.90 & 315 & 155 & 82 & 0.34 \\
\hline & 2 & 8.00 & 770 & 330 & 484 & 0.39 \\
\hline & 3 & - & 1180 & 490 & 1194 & 0.40 \\
\hline \multirow{3}{*}{3} & 1 & 3.20 & 280 & 105 & 39 & 0.42 \\
\hline & 2 & 9.30 & 600 & 270 & 301 & 0.37 \\
\hline & 3 & - & 830 & 470 & 911 & 0.26 \\
\hline
\end{tabular}




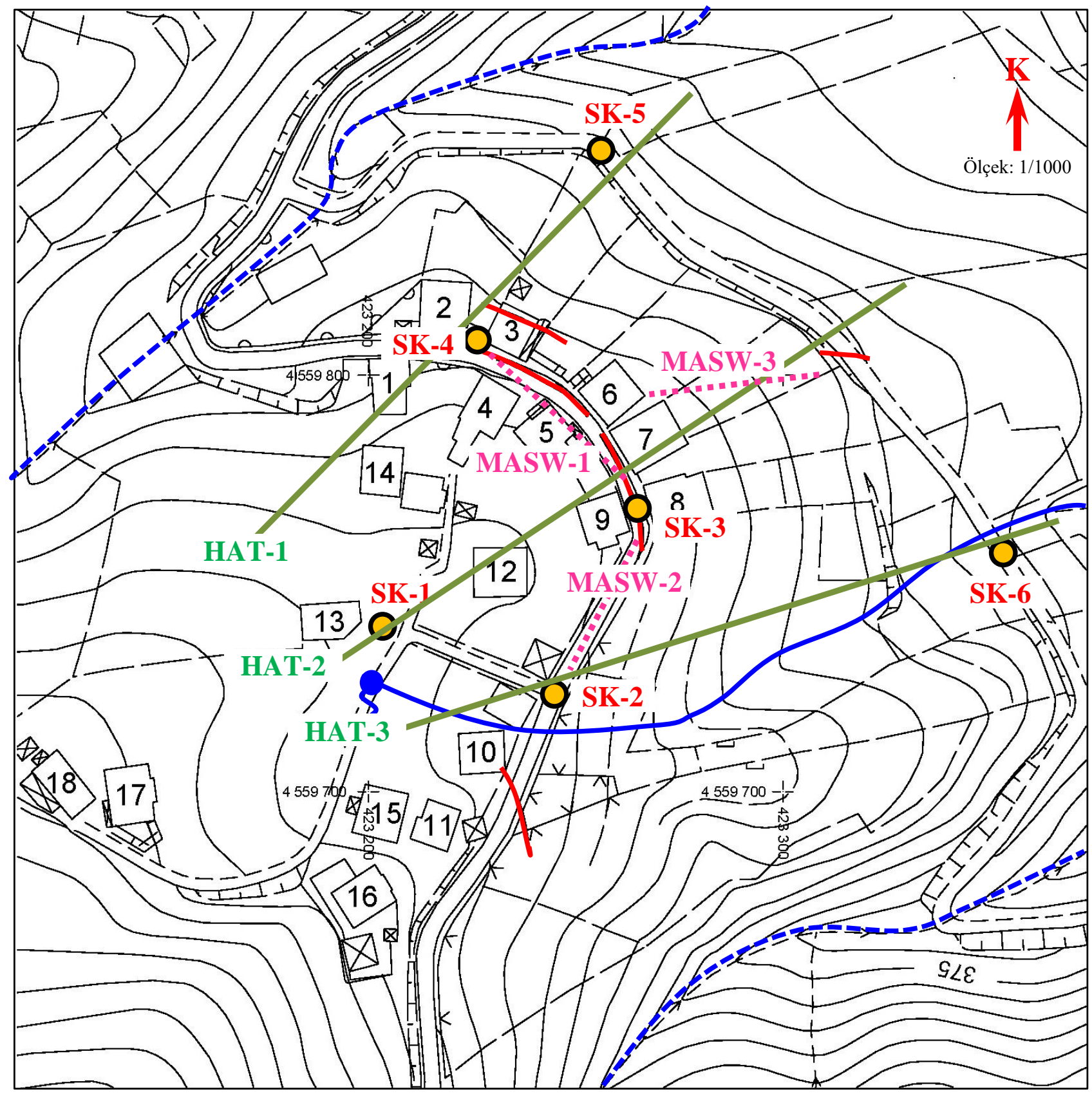

Şekil 4: Sondaj ve MASW lokasyonlarını, çekme gerilmesi çatlakları ve etüt hatlarının konumunu gösteren hali hazır harita (Yapı hasarları 3, 6, 7 ve 8 ile gösterilen evlerde meydana gelmiştir, kırmızı çizgiler gerilme çatlaklarını mavi çizgiler ise dere ve kuru dereleri göstermektedir, HAT: etüt hattı, SK: sondaj kuyusu, MASW: çok kanallı yüzey dalgası etüt hattı) 

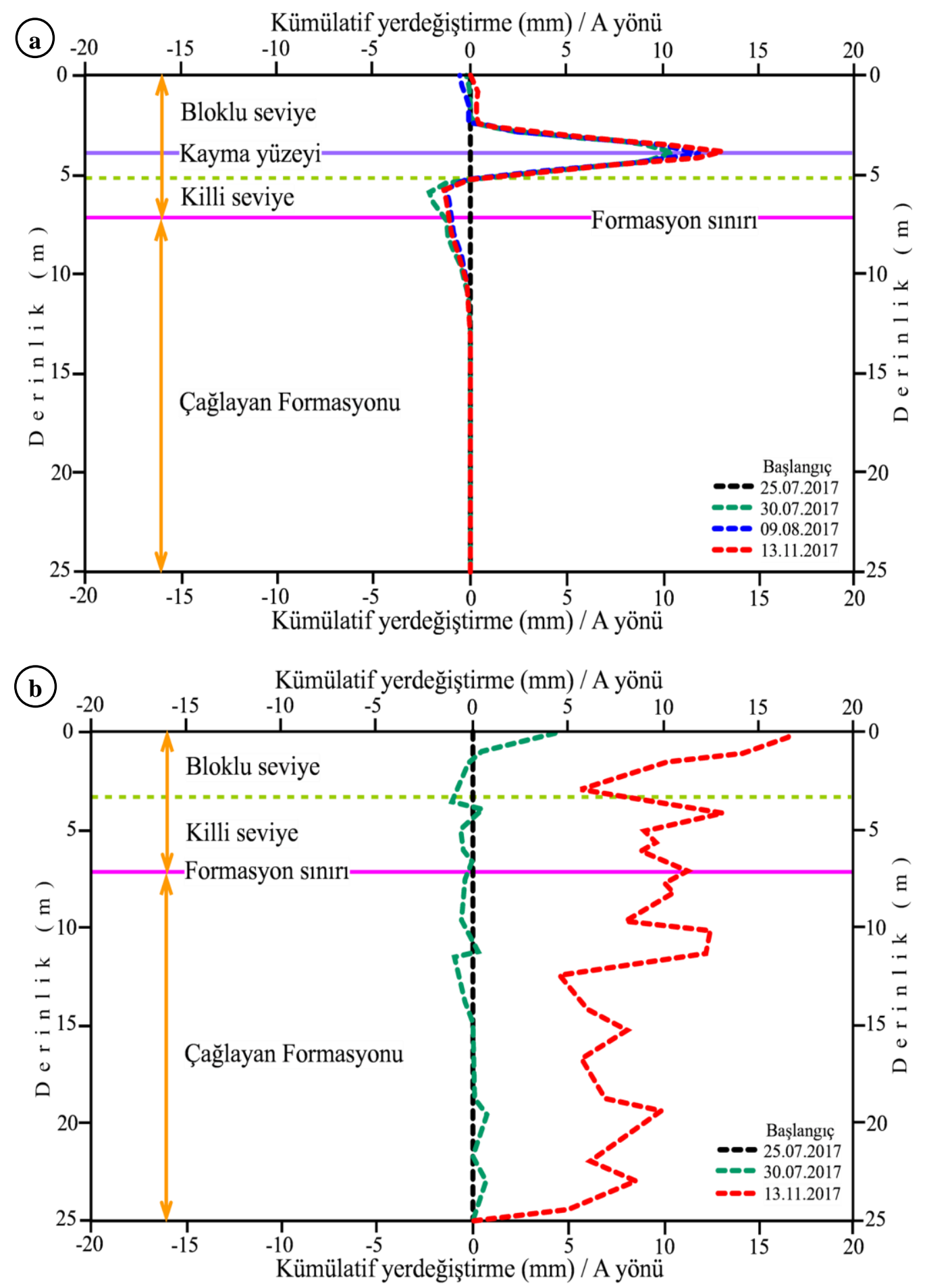

Şekil 5: (a) SK-4 ve (b) SK-5 nolu kuyulara ait inklinometre okumalarında tespit edilmiş derinlik-hareket miktarı ilişkisini gösteren grafikler 


\subsection{Laboratuvar Çalışmaları}

Sondajlardan derlenen örselenmemiş ve örselenmiş zemin örnekleri üzerinde dane boyu dağılımı, kıvam limitleri, su muhtevası ve birim hacim ağırlık özelliklerini belirlemeye yönelik deneyler yapılmıştır (ASTM 2005, 2007, 2009). Örselenmiş zemin örnekleri Birleştirilmiş Zemin Sınıflamasına (USCS) göre sınıflandırılmıştır (ASTM 2006). Laboratuvar deneyleri sonucunda yamaç molozunun zemin sınıfı düşük plastisiteli kil (CL) olarak belirlenmiş olup, ortalama su içeriği ve birim hacim ağırlığı ise sırasıyla $\% 36.1$ ve $17.07 \mathrm{kN} / \mathrm{m}^{3}$ olarak saptanmıştır. Zemine ait kayma dayanımı parametrelerini (kohezyon ve içsel sürtünme açısı) belirlemek için 0.0-7.0 m arasındaki derinliklerden alınan numuneler üzerinde deformasyon kontrollü kesme kutusu deneyleri yapılmıştır (ASTM 2017). Deney sonuçlarına göre ortalama doruk parametreler $\mathrm{c}_{\mathrm{p}}=20.93 \mathrm{kPa}$ ve $\phi_{\mathrm{P}}=14.5^{\circ}$ olarak, artık parametreler ise $\mathrm{c}_{\mathrm{r}}=17.35 \mathrm{kPa}$ ve $\phi_{\mathrm{r}}=10.7^{\circ}$ olarak belirlenmiştir (Tablo 3).

Tablo 3: Zemine ait indeks, fiziksel ve dayanım özellikleri

\begin{tabular}{|c|c|c|c|c|c|c|c|c|c|c|c|c|c|}
\hline \multirow{3}{*}{$\begin{array}{c}\text { Kuyu } \\
\text { no }\end{array}$} & \multirow{3}{*}{$\begin{array}{c}\text { Örnek } \\
\text { derinliği } \\
(\mathbf{m})\end{array}$} & \multicolumn{2}{|c|}{ Elek analizi } & \multirow{3}{*}{$\begin{array}{l}\text { USCS } \\
\text { zemin } \\
\text { sinıfi }\end{array}$} & \multirow{3}{*}{$\begin{array}{c}\omega \\
(\%)\end{array}$} & \multirow{3}{*}{$\begin{array}{c}\gamma_{\mathbf{n}} \\
\left(\mathbf{k N} / \mathbf{m}^{3}\right)\end{array}$} & \multicolumn{3}{|c|}{ Kivam Limitleri (\%) } & \multicolumn{4}{|c|}{ Kesme kutusu } \\
\hline & & \multirow{2}{*}{\begin{tabular}{|c|}
$\# 10$ \\
kalan \\
$(\%)$
\end{tabular}} & \multirow{2}{*}{$\begin{array}{c}\# 200 \\
\text { geçen } \\
(\%)\end{array}$} & & & & \multirow[b]{2}{*}{$\mathbf{L L}$} & \multirow[b]{2}{*}{ PL } & \multirow[b]{2}{*}{ PI } & \multicolumn{2}{|c|}{ Doruk } & \multicolumn{2}{|c|}{ Artık } \\
\hline & & & & & & & & & & $\begin{array}{c}\mathbf{c}_{\mathrm{p}} \\
(\mathbf{k P a})\end{array}$ & $\begin{array}{l}\phi_{\mathrm{p}} \\
\left(^{0}\right)\end{array}$ & $\begin{array}{c}\mathrm{c}_{\mathbf{r}} \\
(\mathrm{kPa})\end{array}$ & $\begin{array}{l}\phi_{\mathrm{r}} \\
\left({ }^{\circ}\right)\end{array}$ \\
\hline SK-2 & 4.50 & 5.3 & \begin{tabular}{|l|}
50.9 \\
\end{tabular} & $\mathrm{CL}$ & 39.8 & 17.17 & 45.2 & 21.8 & 23.4 & 18.55 & 15.6 & - & - \\
\hline SK-2 & 5.50 & 17.2 & 57.6 & CL & 38.9 & 16.87 & 44.0 & 22.9 & 21.1 & 22.80 & 16.4 & 18.36 & 12.6 \\
\hline SK-3 & 2.50 & 14.5 & 73.7 & $\mathrm{CL}$ & 40.1 & 16.78 & 47.5 & 22.7 & 24.8 & 21.44 & 10.7 & 16.67 & 7.6 \\
\hline SK-3 & & 1.5 & 57.9 & $\mathrm{CL}$ & 30.5 & 17.27 & 43.2 & 20.2 & 2. & 15.04 & 15.3 & 13.78 & 10.8 \\
\hline SK-6 & 2.50 & 35.1 & 59.0 & $\mathrm{CL}$ & 31.0 & 17.07 & 42.5 & 21. & 21. & 26.83 & 14.3 & 20.59 & 11.6 \\
\hline Ort. & - & - & - & - & 36.1 & 17.07 & 44.5 & 21.7 & 22.8 & 20.93 & 14.5 & 17.35 & 10.7 \\
\hline
\end{tabular}

\subsection{Duraylılık Analizleri}

Çalışma alanındaki yenilme sorununun gözlendiği yamacın duraylılık açısından araştırılmasında limit denge analizi yapan "Slide v6.0" (Rocscience 2011a) ve sayısal analiz yapan sonlu elemanlar tabanl1 "Phase ${ }^{2}$ v8.0" (Rocscience 2011b) bilgisayar programlarından yararlanılmıştır. Sahada yapılan araştırma sondajlarından ve jeofizik etütlerden elde edilen veriler kullanılarak 3 etüt hattı için jeolojik kesitler hazırlanmış (Şekil 6) ve bu profiller yardımıyla duraylılık analizlerinde kullanılacak modeller çizilmiştir. İlk olarak yenilmenin geliştiği yamacın duraylılığı limit denge analizleri ile araştırılmış daha sonra sayısal analizler yapılarak elde edilen sonuçlar karşılaştırılmıştır.

\subsubsection{Limit Denge Analizi}

"Slide" programı zemin şevleri için güvenlik sayılarının hesaplanmasında yaygın olarak kullanılan bir bilgisayar yazılımıdır. Program ile değişken özellikler gösteren, farklı geometrilerdeki yüzeyler gibi basit ve karmaşık problemler modellenebilmekte, boşluk suyu basıncının etkisi, zemin özellikleri ve çeşitli analiz yöntemleri ile yükleme koşulları belirlenebilmektedir. Ayrıca, programda analiz yaparken heterojen zemin tipleri ve karmaşık stratigrafik durumlar da değerlendirilebilmektedir.

Yamaçlar doğal şevler olduğundan duraylı olabilmesi için hesap edilen güvenlik sayısı $\left(\mathrm{G}_{\mathrm{s}}\right)$ değerinin en az 1 yani limit denge durumunda olması gerekmektedir. $\mathrm{G}_{\mathrm{s}}<1$ olduğu zaman limit denge durumu bozulmakta ve yamaç duraysız hale gelmektedir. Yol ve yarma şevleri gibi doğal olmayan yüksek eğim açılı şevlerde ise hesap edilen güvenlik sayısı $\left(\mathrm{G}_{\mathrm{s}}\right)$ değerinin duraylılık için Gs>1.5 olması gerekmektedir (Mines Branch, Canada 1972). Etüt hatları için analizler yapılırken kaymanın başladığı varsayımından kesme kutusu deneyleri ile elde edilen Tablo 3 'te verilen ortalama artık kayma dayanımı parametreleri kullanılmıştır. Bu nedenle, zeminin doğal durumu için statik koşullardaki kabul edilebilir güvenlik sayısı 1 olarak seçilmiştir.

Analizlerde Mohr-Coulomb yenilme kriteri kullanılmış olup, kayma şekli olarak dairesel ve birleşik kayma türleri seçilmiştir. Zeminin uzunluğu kalınlığına göre daha büyük olduğundan ve birleşik kayma şeklinde bir hareket de gözlenebileceğinden limit denge analizlerinde Janbu Yöntemi kullanılmıştır.

1 nolu etüt hattı için yapılan limit denge analizleri sonucunda SK-4 nolu ölçüm kuyusundan tespit edilen yüzeyden 4 $\mathrm{m}$ derindeki kayma yüzeyine ait güvenlik sayısı değerinin $\mathrm{G}_{s}: 0.749$ olduğu belirlenmiştir (Şekil 7a). 2 nolu etüt hattı için yapılan limit denge analizleri sonucunda 8 nolu evi içine alacak şekilde daha alt kotlarda sonlanan iki adet kayma dairesi elde edilmiştir. Bu dairelere ait güvenlik sayısı değerinin sırasıyla $\mathrm{G}_{\mathrm{s}}$ : 0.785 ve 0.984 olduğu belirlenmiştir (Şekil $7 \mathrm{~b}$ ). 3 nolu etüt hattında gerçekleşen duraysızlık başlangıcı beton yolun daha üst kotlarında meydana gelmiştir. Bu duraysızlığın diğer iki etüt hattıyla bağlantılı olup olmadığını araştırmak amacıyla yapılan limit denge analizleri sonucunda 10 nolu evin sınırındaki beton yoldan başlayıp arazideki mevcut durumla uyumlu olacak şekilde alt kotlara kadar ulaşmayan bir adet kayma dairesi elde edilmiştir. Bu kayma yüzeyine ait güvenlik sayısı değeri ise $\mathrm{G}_{s}$ : 0.998 olarak belirlenmiştir (Şekil 7c). 
Etüt hattı 1 ve 2 için yapılan limit denge analizlerindeki kayma mekanizmasının benzer olması aynı doğrultuda gelişmiş iki çatlak sisteminin birbiriyle bağlantı olduğunu ispatlamaktadır. 1 ve 2 nolu etüt hatlarında oluşan kayma yüzeyleri dairesel ve birleşik kayma şeklindedir. Hatların geneli incelendiğinde yenilmenin dairesel yüzeylerle başlayıp ana kaya dokanağına yakın yerlerden düzlemsel yüzeylerle devam ettiği ve tekrar dairesel yüzeylerle topukta sonlandığı görülmektedir. Sonuç olarak, sahadaki yenilme mekanizmasının birleşik kayma modeline uyduğu anlaşılmaktadır. 3 nolu etüt hattındaki kaymanın oluşum mekanizması diğer iki etüt hatlarındaki kayma mekanizmasından farklı olarak daha çok dairesel kayma modeline uymaktadır.

\subsubsection{Sayısal Analiz (FEM-SSR Analizi)}

Limit denge analizlerinin sonuçlarını kontrol etmek için sonlu elemanlar yönteminden yararlanılmıştır. Bu amaçla, yamaca ait olası duraysızlık problemini belirlemek için FEM-SSR yöntemini uygulayan "Phase" "sonlu elemanlar programı kullanılarak güvenlik sayıları belirlenmiştir. Limit denge analizinde kullanılan modeller üzerinde sayısal analizler gerçekleştirilmiştir (Şekil 6). Analizlerde sismik çalışmalar yardımıyla elde edilen deformasyon modülü ( $\left.E_{d}\right)$ ve Poisson oranı (v) değerleri modele tanımlanmıştır. 1, 2 ve 3 nolu etüt hatları için oluşturulan sayısal analiz modellerinde güvenli tarafta kalmak amacıyla deformasyon modülü sırasıyla 145, 82, $39 \mathrm{MPa}$ olarak, Poisson oranı ise $0.33,0.34$ ve 0.42 olarak seçilmiştir (Tablo 2). Sayısal analizler Mohr-Coulomb yenilme kriterine göre yapılmış olup, limit denge analizlerinde kullanılan ortalama artık kayma dayanımı parametreleri ve birim hacim ağırlığı değerleri dikkate alınmıştır.

Yamacın duraylılığı FEM-SSR yöntemiyle incelendiğinde güvenlik sayısı değerleri 1 nolu etüt hattı için $\mathrm{G}_{\mathrm{s}}$ : $0.56,2$ nolu hat için $\mathrm{G}_{\mathrm{s}}: 0.58$ ve 3 nolu etüt hattı için ise $\mathrm{G}_{\mathrm{s}}$ : 0.80 olarak belirlenmiştir (Şekil 8d, e, f). Bu sonuçlar 1ve 2 nolu etüt hatları için limit denge analiziyle de uyumlu olarak yamacın duraysız olduğunu göstermektedir. Limit denge analizleriyle belirlenen ve güvenlik sayısı 1 'den küçük kayma yüzeylerinin dağılımı FEM-SSR yöntemiyle belirlenen duraysız alanın içinde kalmaktadır. 3 nolu etüt hattı ile ilgili olarak FEM-SSR sonuçları, limit denge analiz yöntemiyle elde edilen sonuçlara göre daha tutucu davranarak kayma riskli alanın boyutlarını alt kotlara kadar ilerletmiştir. Ancak, limit denge analiz yöntemiyle uyumlu olacak şekilde kaymanın başlangıç kısmını 10 nolu evi de içine alacak şekilde sınırlandırmıştır. Etüt hatları için FEM-SSR yöntemi ile yapılan analiz sonuçları sahadaki yenilme mekanizmasının birleşik kayma (dairesel+düzlemsel) modeline uyduğunu göstermektedir.

Yapılan limit denge ve sayısal analizler sonucunda yenilmenin gerileyen biçimde devam etme olasılığının olduğu saptanmıştır. 1 ve 2 nolu etüt hatları incelendiğinde sahada olması muhtemel kaymaların iki ayrı bölümde gruplaştığı belirlenmiştir. İlk grup kayma daireleri beton yolda başlayıp yamaç yüzeyinde, ikinci grup kayma daireleri ise yamaçta başlayıp alt kotlarda son bulmaktadır. Yani, bu alanda birbirinden bağımsız iki yenilmenin gerçekleşme olasılığı vardır. 3 nolu etüt hattında ise bu iki analizden farklı olarak tek bir alanda kayma daireleri yoğunlaşmıştır.

Sonuç olarak limit denge ve FEM-SSR duraylılık analizleri inklinometre sonuçlarıyla da uyumlu olarak benzer sonuçlar vermiş ve yamacın desteklemesi gerekliliğini ortaya koymuştur. 


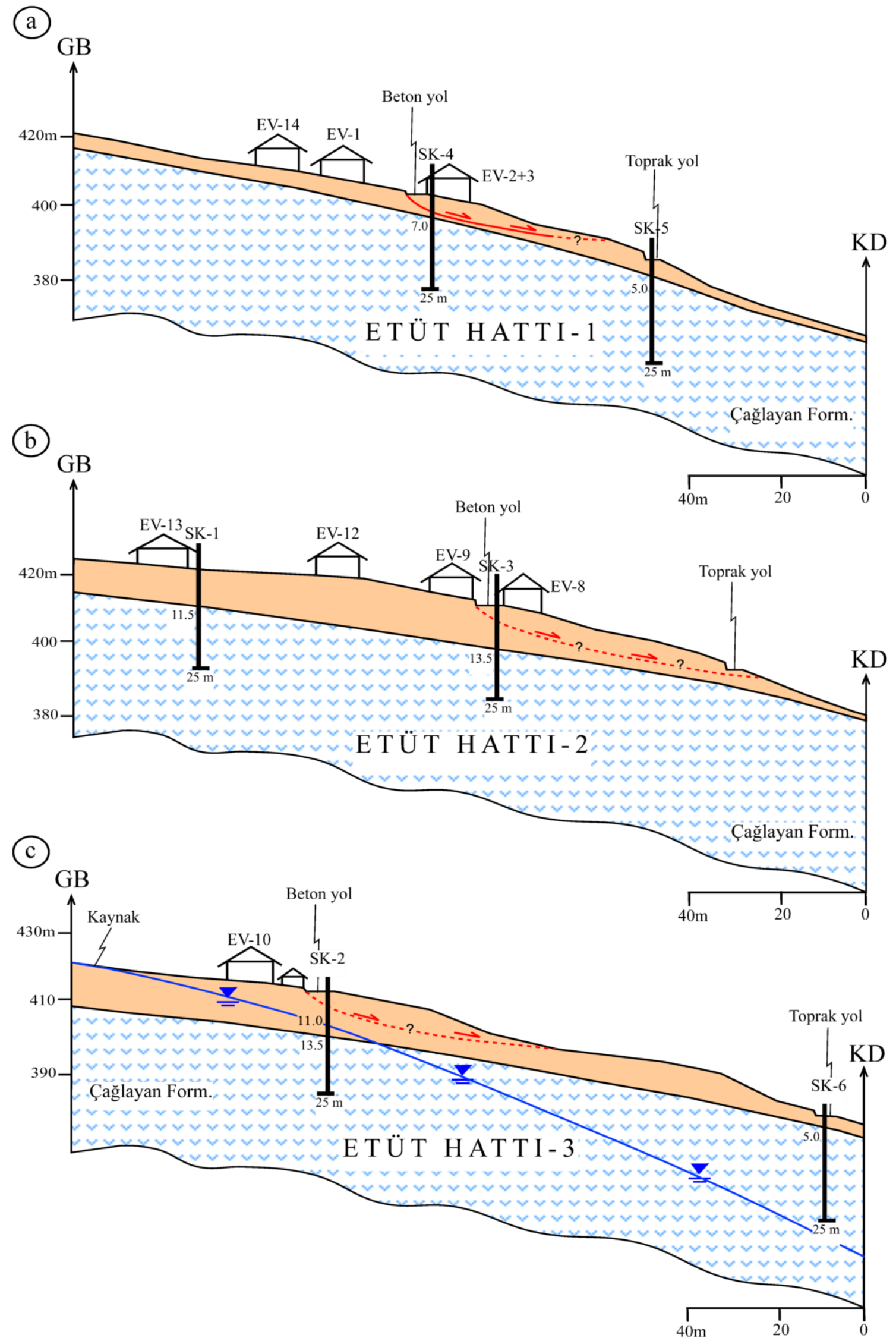

Şekil 6: Etüt hatları boyunca zemin profilindeki değişimi gösteren jeolojik kesitler 

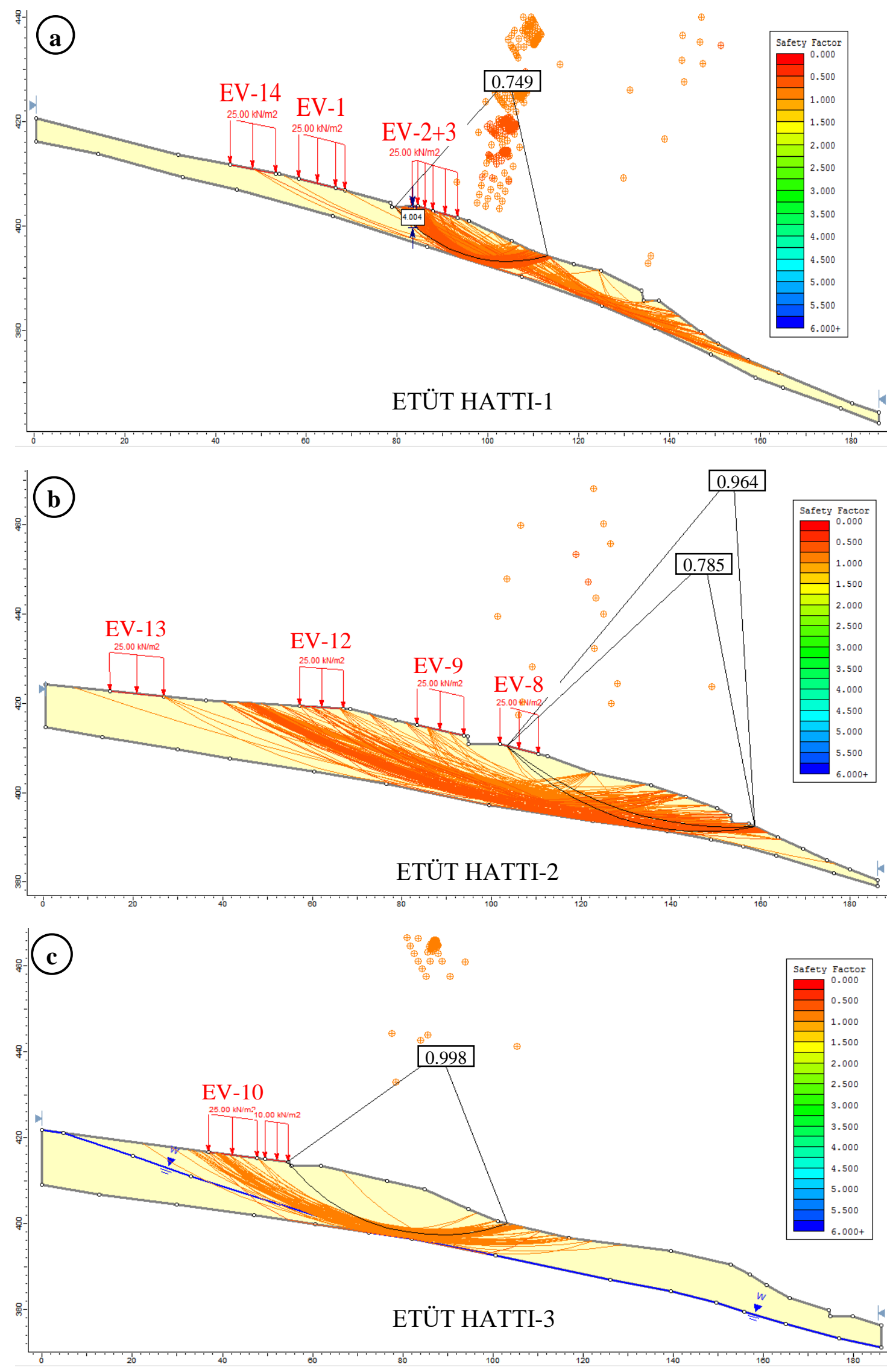

Şekil 7: Etüt hatları için yapılan (a-c) limit denge analizi sonuçları 

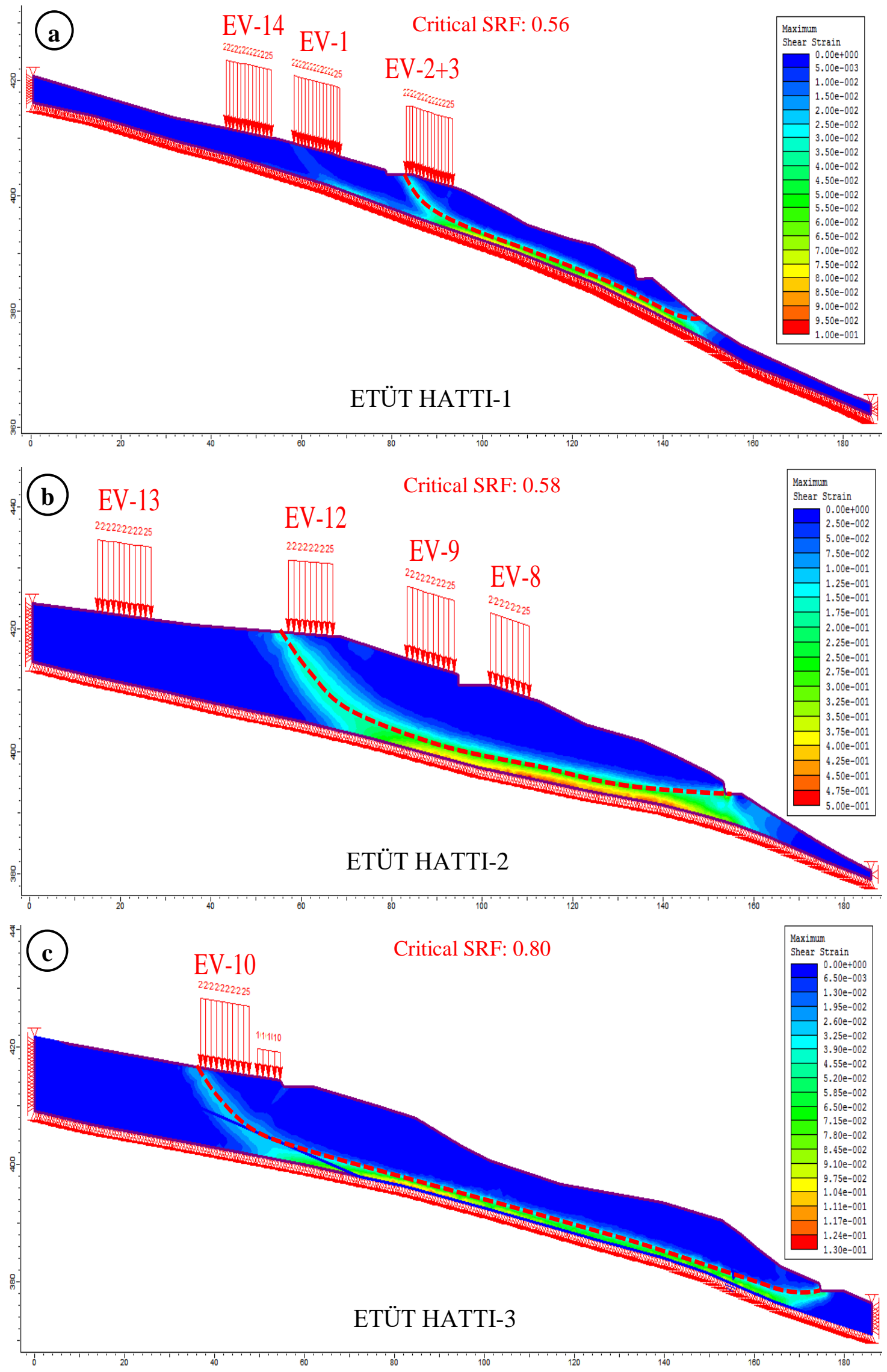

Şekil 8: Etüt hatları için yapılan (a-c) sayısal analiz sonuçları 


\section{Sonuçlar ve Öneriler}

Bu çalışma kapsamında, Gündoğan (Ardeşen-Rize) Köyü yerleşim alanının üstünde bulunduğu yamaçta meydana gelen duraysızlık sorunu jeoteknik açıdan incelenmiştir. Elde edilen sonuçlar aşağıda özet olarak sunulmuştur;

1) Duraysızlık probleminin gözlendiği yamaçta yapılan sondaj ve jeofizik çalışmaları sonucunda ana kaya ve yamaç molozu sınırı net bir şekilde ortaya konmuş ve yamaç molozu kalınlığının 5.0-16.5 m arasında değiştiği saptanmıştır.

2) Yamaç molozundan alınan örselenmiş numunelerde zemin sınıfının düşük plastisiteli kil (CL) olduğu belirlenmiştir. Kayma dayanımı parametrelerini saptamak için örselenmemiş örnekler üzerinde yapılan kesme kutusu deneylerinde ortalama $c_{\mathrm{p}}$ ve $c_{\mathrm{r}}$ değerleri sırasıyla $20.93 \mathrm{kPa}$ ve $14.5 \mathrm{kPa}$ olarak, ortalama $\phi_{\mathrm{p}}$ ve $\phi_{\mathrm{r}}$ değerleri ise sirasıyla $14.5^{\circ}$ ve $10.7^{\circ}$ olarak tespit edilmiştir.

3) Yapılan inklinometre okumalarına göre kaymanın yüzeyden $4 \mathrm{~m}$ derinlikte ve ölçüm süresindeki kaymanın 0.09 $\mathrm{mm} /$ gün hızında KD yönüne doğru olduğu belirlenmiştir.

4) Çalışma alanındaki yamacın duraylılığını araştırmak için Janbu yöntemi kullanılarak limit denge analizi ve FEMSSR yöntemi kullanılarak sayısal analizler yapılmıştır. Yapılan duraylılık analizlerinde güvenlik sayısı değerlerinin limit denge durumu için kabul edilen Gs: 1 değerinden oldukça küçük olduğu belirlenmiştir. Analiz sonuçları, duraysızlık sorununun gerileyen şekilde devam etme riski taşıdığını ve yamacın dengede olmadığını göstermektedir.

5) Yamaçta meydana gelen duraysızlık sorunu şu an için yavaşlamış olsa da sonraki dönemlerde ileri boyutlara ulaşmaması için 1slah edilmesinin gerekli olduğu düşünülmektedir. Kazıklı destekleme yönteminin uygulanması durumunda kazıkların ana kaya içine inecek şekilde soketlenmesi gerekmektedir. Demir donatılı kazıkların yeraltı suyunun akışını engellememesi için yamacın doğrultusu boyunca birer boşluk bırakarak imal edilmesi ve imalat sonrasında yanal toprak basıncıyla deforme olmaması için başlık kirişi ile sabitlenmesi gereklidir. Sahada uygulanacak fore kazık tipinin seçimine, sayısının ve sıra adedinin belirlenmesine hazırlanacak fore kazık projesi ile karar verilmelidir.

\section{Teşekkür}

Yazarlar bu çalışmayı destekleyen Rize Valiliği İl Afet ve Acil Durum Müdürlüğü’ne (AFAD) teşekkür ederler.

\section{Kaynaklar}

Akgün A., Bulut F., (2007), GIS-based landslide susceptibility for Arsin-Yomra (Trabzon, North Turkey) Region, Environmental Geology, 51, 1377-1387.

Akgün A., Dağ S., Bulut F., (2008), Landslide susceptibility mapping for a landslide-prone area (Findikli, NE of Turkey) by likelihoodfrequency ratio and weighted linear combination models, Environmental Geology, 54, 1127-1143.

Akgün A., Sezer E.A., Nefeslioğlu H.A., Gökçeoğlu C., Pradhan B., (2012), An easy-to-use MATLAB program (MamLand) for the assessment of landslide susceptibility using a Mamdani fuzzy algorithm, Computers and Geosciences, 38(1), 23-34.

Alemdağ S., Akgün A., Kaya A., Gökçeoğlu C., (2014), A large and rapid planar failure: causes, mechanism and consequences (Mordut, Gumushane, Turkey), Arabian Journal of Geoscience, 7(3), 1205-1221.

Alemdă̆ S., Kaya A., Karadağ M., Gürocak Z., Bulut F., (2015), Utilization of the limit equilibrium and finite element methods for the stability analysis of the slope debris: an example of the Kalebasi district (NE Turkey), Journal of African Earth Science, 106, 134146.

Althuwaynee O.F., Pradhan B, Lee S., (2012), Application of an evidential belief function model in landslide susceptibility mapping, Computers and Geosciences, 44, 120-135.

ASTM, (2005), Standard test methods for liquid limit, plastic limit and plasticity index of soils, Annual Book of ASTM Standards, ASTM D4318, Philedelphia, USA.

ASTM, (2006), Standard practice for classification of soils for engineering purposes (Unified Soil Classification System), Annual Book of ASTM Standards, ASTM D2487, Philedelphia, USA.

ASTM, (2007), Standard test method for particle-size analysis of soils, Annual Book of ASTM Standards, ASTM D422, Philedelphia, USA.

ASTM, (2009), Standard test methods for laboratory determination of density (unit weight) of soil specimens, Annual Book of ASTM Standards, ASTM D7263-09, Philedelphia, USA.

ASTM, (2017), Standard test method for consolidated undrained direct simple shear testing of fine grain soils, Annual Book of ASTM Standards, ASTM D6528-17, Philedelphia, USA.

Avşar O., Akgun H., Kockar M.K., (2014), Investigation of the failure mechanism and stabilization of a landslide in weathered tuffite, Giresun, northeastern Turkey, Environmental Earth Science, 72, 3723-3740.

Ayalew L., Yamagishi H., Ugawa N., (2004), Landslide susceptibility mapping using GIS-based weighted linear combination, the case in Tsugawa area of Agano river, Niigate prefecture, Japan, Landslides, 1, 73-81.

Castellanos Abella E.A., Van Westen C.J., (2007), Generation of a landslide risk index map for Cuba using spatial multi-criteria evaluation, Landslides, 4, 311-325.

Çan T., Nefeslioğlu H.A., Gökçeoğlu C., Sönmez H., Duman T.Y., (2005), Susceptibility assessments of shallow earthflows triggered by heavy rainfall at three catchments by logistic regression analyses, Geomorphology, 72, 250-271.

Dağ S., (2007), Çayeli (Rize) ve çevresinin istatistiksel yöntemlerle heyelan duyarlılık analizi, Doktora Tezi, Karadeniz Teknik Üniversitesi, Fen Bilimleri Enstitüsü, Trabzon, Türkiye. 
Dağ S., Bulut F., (2012), Coğrafi bilgi sistemleri tabanlı heyelan duyarlılık haritalarının hazırlanmasına bir örnek: Çayeli (Rize, KD Türkiye), Jeoloji Mühendisliği Dergisi, 36(1), 35-62.

Ercanoğlu M., Gökçeoğlu C., (2002), Assessment of landslide susceptibility for a landslide-prone area (North of Yenice, NW Turkey) by fuzzy approach, Environmental Geology, 41, 720-730.

Gökçeoğlu C., Aksoy H., (1996), Landslide susceptibility mapping of the slopes in the residual soils of the Mengen region (Turkey) by deterministic stability analyses and image processing techniques, Engineering Geology, 44, 147-161.

Gürocak Z., Alemdağ S., Zaman M., (2008), Rock slope stability and excavatability assessment of rocks at the Kapikaya dam site eastern Turkey, Engineering Geology, 96(1-2), 17-27.

Güven İ.H., (1993), Doğu Pontidlerin jeolojisi ve 1/250000 ölçekli komplikasyonu, MTA, Ankara.

Jeldes I., Vence N., Drumm E., (2013), An approximate solution to the Sokolovskil concave slope at limiting equilibrium, International Journal of Geomechanics, 15(2), 1-8.

Kahatadeniya K.S., Nanakorn P., Neaupane K.M., (2009), Determination of the critical failure surface for slope stability analysis using antcolony optimization, Engineering Geology, 108, 133-141.

Kaya A., Akgün A., Karaman K., Bulut F., (2015), Understanding the mechanism of a slope failure on nearby a highway tunnel route by different slope stability analysis methods: a case from NE Turkey, Bulletin of Engineering Geology and the Environment, 75(3), 945-958.

Kaya A., Alemdağ S., Dağ S., Gürocak Z., (2016), Stability assesment of high steep cut slope debris on a landslide Gumushane NE Turkey, Bulletin of Engineering Geology and the Environment, 75(1), 89-99.

Kaya A., Bulut F, Dağ S., (2018), Bearing capacity and slope stability assessment of rock masses at the Subasi viaduct site, NE Turkey, Arabian Journal of Geoscience, doi: 10.1007/s12517-018-3477-7.

Ketin İ., (1966), Tectonic units of Anatolia, Journal of General Directorate of Mineral Research and Exploration (MTA), 66, 23-34.

Kıncal C., Akgün A., Koca M.Y., (2009), Landslide susceptibility assessment in the Izmir (West Anatolia, Turkey) city center and its near vicinity by the logistic regression method, Environmental Earth Sciences, 59, 745-756.

Lee S., (2005), Application of logistic regression model and its validation for landslide susceptibility mapping using GIS and remote sensing data, International Journal of Remote Sensing, 26(7), 1477-1491.

Liu F., Zhao J., (2013), Limit analysis of slope stability by rigid finite element method and linear programming considering rotational failure, International Journal of Geomechanics, 13(6), 827-839.

Mines Branch, Canada, (1972), Tentative design guide for mine waste embankments in Canada, Department of Energy, Mines and Resources, Canada.

Nefeslioğlu H.A., Gökçeoğlu C., Sönmez H., (2008), An assessment on the use of logistic regression and artificial neural networks with different sampling strategies for the preparation of landslide susceptibility maps, Engineering Geology, 97, 171-191.

Ösna T., Sezer E.A., Akgün A., (2014), GEOFIS: an integrated tool for the assessment of landslide susceptibility, Computers and Geosciences, 66, 20-30.

Pradhan B., Sezer E.A., Gökçeoğlu C., Buchroithner M.F., (2010), Landslide susceptibility mapping by neuro-fuzzy approach in a landslide prone area (Cameron Highland, Malaysia), IEEE Transactions on Geosciences Remote Sensing, 48(12), 4164-4177.

Reichenbacha P., Rossia M., Malamudb B.D., Mihirb M., Guzzettia F., (2018), A review of statistically-based landslide susceptibility models, Earth-Science Reviews, 180, 60-91.

Rocscience, (2011a), Slide v6.0, 2 D limit equilibrium slope stability analysis, Rocscience Inc., Toronto, Ontario, Canada.

Rocscience, (2011b), Phase ${ }^{2}$ v8.0 finite element analysis for excavations and slopes, Rocscience Inc., Toronto, Ontario, Canada.

Romer C., Ferentinou M., (2016), Shallow landslide susceptibility assessment in a semiarid environment-A Quaternary catchment of KwaZulu-Natal, South Africa, Engineering Geology, 201, 29-44.

Samia J., Temme A., Bregt A., Wallinga J., Guzzetti F., Ardizzone F., Rossi M., (2017), Characterization and quantification of path dependency in landslide susceptibility, Geomorphology, 292, 16-24.

Sezer E.A., Pradhan B., Gökçeoğlu C., (2011), Manifestation of an adaptive neuro-fuzzy model on landslide susceptibility mapping: Klang valley, Malaysia, Expert Systems and Applications, 38(7), 8208-8219.

Varnes D.J., (1978), Slope movement types and processes, Landslides-analysis and control: National Research Council, Transportation Research Board, Washington D.C., 176ss.

Yeşilnacar E., Topal T., (2005), Landslide susceptibility mapping: A comparison of logistic regression and neural networks methods in a medium scale study, Hendek region (Turkey), Engineering Geology, 79, 251-266. 